\title{
Accuracy of Cardiogoniometry in Diagnosis of Coronary Artery Disease in Patients with Angina Pectoris
}

\author{
Seyed Masoud Seyedian, Farzaneh Ahmadi, Samira Maalhagh Fard, Abdolrahim Nejat Bakhsh \\ Cardiovascular Disease Research Center, Ahvaz Jundishapur University of Medical Sciences, Ahvaz, Iran \\ Email: samiramaalhagh@gmail.com
}

How to cite this paper: Seyedian, S.M., Ahmadi, F., Fard, S.M. and Bakhsh, A.N. (2016) Accuracy of Cardiogoniometry in Diagnosis of Coronary Artery Disease in Patients with Angina Pectoris. World Journal of Cardiovascular Diseases, 6, 383-390. http://dx.doi.org/10.4236/wjcd.2016.611043

Received: June 2, 2016

Accepted: October 31, 2016

Published: November 3, 2016

Copyright (c) 2016 by authors and Scientific Research Publishing Inc. This work is licensed under the Creative Commons Attribution International License (CC BY 4.0).

http://creativecommons.org/licenses/by/4.0/ (c) (i) Open Access

\begin{abstract}
Background: Cardiogoniometry (CGM) is a novel non-invasive technique for quantitative three-dimensional vectorial analysis of myocardial depolarization and repolarization. We aimed to determine the diagnostic value of cardiogoniometry for the identification of coronary artery disease (CAD) in patients with history of chest pain. Materials and Methods: Cardiogoniometry was performed in 190 patients with history of chest pain prior to diagnostic coronary angiography. Then cardiogoniometry parameters correlated with angiography findings to determine accuracy of cardiogoniometry for diagnose of CAD. Result: Cardiogoniometry showed a sensitivity of $72 \%$ and a specificity of $60 \%$, which was less sensitive than perfusion scan but more sensitive than the ECG and comparable with exercise ECG. The specificity was less than these three methods. Conclusions: Cardiogoniometry is a new, noninvasive method which is helpful in identifying patients with coronary artery disease and can be performed at rest and free of risk such as radiation exposure, and also is suitable for patients who are not able to exercise.
\end{abstract}

\section{Keywords}

Angina, Ischemia, Coronary Artery Disease, Cardiogoniometry, Non-Invasive Techniques

\section{Introduction}

In this century, cardiovascular disease is responsible for $30 \%$ of total mortalities, and in 2010 was the most common cause of death in American men and women. Of which about $20 \%$ of cases, is caused by IHD. The most common cause of IHD is coronary artery disease (CAD). IHD can be presented as typical chest pain, atypical chest pain or 
Asymptomatic. Coronary artery disease is the most common cause of death in the past decade throughout the world [1]. Now Gold standard diagnosis of diagnostic coronary angiography is angiography, an invasive procedure. Diagnostic coronary angiography is defined as coronary artery lumen diameter reducing more than $50 \%$. Currently the most widely used non-invasive tests for diagnosis of diagnostic coronary angiography is thallium perfusion scan and exercise ECG. Diagnostic coronary angiography diagnosis, especially in patients who do not have the ability to do Stress test can be difficult and the standard 12-lead ECG at rest do not have high sensitivity and specificity [2].

So using cardiogoniometry (CGM) as a non-invasive method at rest and with high precision for diagnostic coronary angiography diagnosis in patients with chest pain is very important, effective and inexpensive.

In studies the sensitivity and specificity of this method for diagnosis of diagnostic coronary angiography is higher than the exercise test, so is the safe and good alternative for it [3].

Cardiogoniometry is the novel non-invasive procedure and at rest, using the principles of ECG and 3-dimensional investigation of electrical current in the depolarization and repolarization states to find ischemia and infarction in different parts of the myocardium [4] [5] [6] [7].

The results of cardiogoniometry with the bank information stored in the memory of the relevant software were analyzed and give detailed information of the heart muscle condition in the coronary arteries bed [5] [6].

Ischemic heart disease (IHD) mainly is created by atheromatous plaque that gradually narrow or occlude coronary arteries. Other causes include endothelial dysfunction, microvascular disease and vasospasm that either alone or in combination with atherosclerosis are due to myocardial ischemia. The predominant symptom in IHD is chest discomfort. Angina is a pain in the chest and adjacent areas caused by activity and is also described as squeezing, heaviness, tightness, numbness or tingling. The pain is in the retrosternal area and spread to other parts is also common. In some patients atypical angina or angina equivalent, such as epigastric pain, exercise intolerance, dyspnea and fatigue is a symptom too. The angina caused by imbalance between oxygen supply and demand. Non-invasive tests give us useful diagnostic and prognostic data. The accuracy and reliability of any test not only the sensitivity and specificity but also depends on the prevalence and pretest probability of disease. The maximum value of these tests is when there is moderate risk for disease. The sensitivity of test used for screening coronary artery disease is more important than its specificity. The sensitivity and specificity of exercise test (and also cardiogoniometry) with the use of angiography as the gold standard for diagnosis is limited and can create bias so that increase sensitivity and decrease specificity because the patients selected for angiography more likely to have coronary artery disease.

The sensitivity and specificity of exercise test is $68 \%$ and $77 \%$ respectively, perfusion scan is $90 \%, 82 \%$ [1] and those of ECG is $53 \%$ and $75 \%$ [7] [8]. In cardiogoniometry by using four electrodes A, D, Ve and null the frontal and oblique sagittal plane (OSP) and 
3-dimensional registration of the heart is obtained (Figure 1). A microprocessor measures the variables over a period of 15 seconds from each heart cycle. In each patient the mean value and the standard deviation of all parameters measured during the registration period are calculated by the computer (Figure 2). In this study a cardiogoniogram was considered abnormal if one of the angles deviated by more than two standard deviations from the mean of the normal subjects which determined automatically by device [9]. Since the cardiogoniometry gives 12-lead ECG in addition to vectorcardiography it can do accurate software surveys for differential diagnosis of ischemia in patients. It also gives precise information of myocardial activity in different coronary artery beds and left ventricular hypertrophy (LVH).

\section{Materials and Methods}

In this analytical epidemiological study 190 patients referred for coronary angiography were selected with random sampling. The patients were evaluated for the presence of angina pectoris in past medical history. Angina is defined as chest pain or discomfort, atypical angina or angina equivalent, such as epigastric pain and exertional dyspnea.

Exclusion criteria was patients with acute coronary syndromes requiring emergency coronary angiography.

All patients underwent cardiogoniometry the day before the angiograghy. After coronary angiography to determine the sensitivity and specificity of cardiogoniometry, data were statistically analyzed.

The parameters of cardiogoniometry were registered by cardiologic explorer device manufactured by Germany's Enverdise Company using five leads placed at certain points of the body. Then the data were analyzed by device software and results were reported as normal or pathological (positive and negative).

Diagnostic angiography was performed for all participants, using left and right Judkins Catheters through the femoral artery with Germany's Siemens Axiom Artis. Interpretation of the results of angiography was performed by a cardiologist who was blind to cardiogoniometry test results.

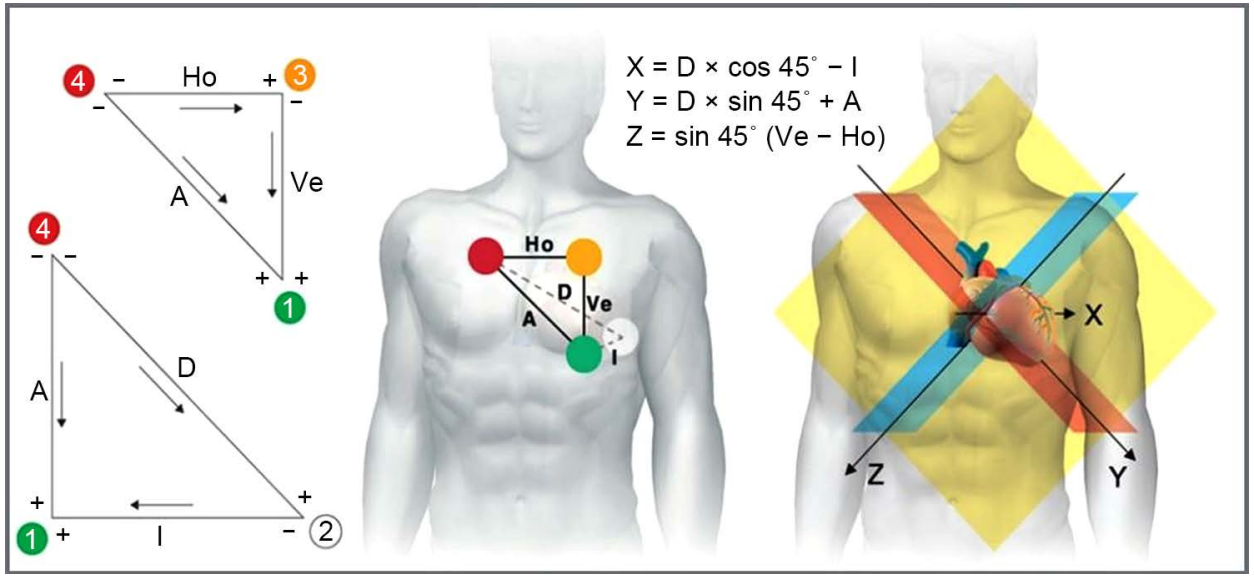

Figure 1. Placement of electrodes. 


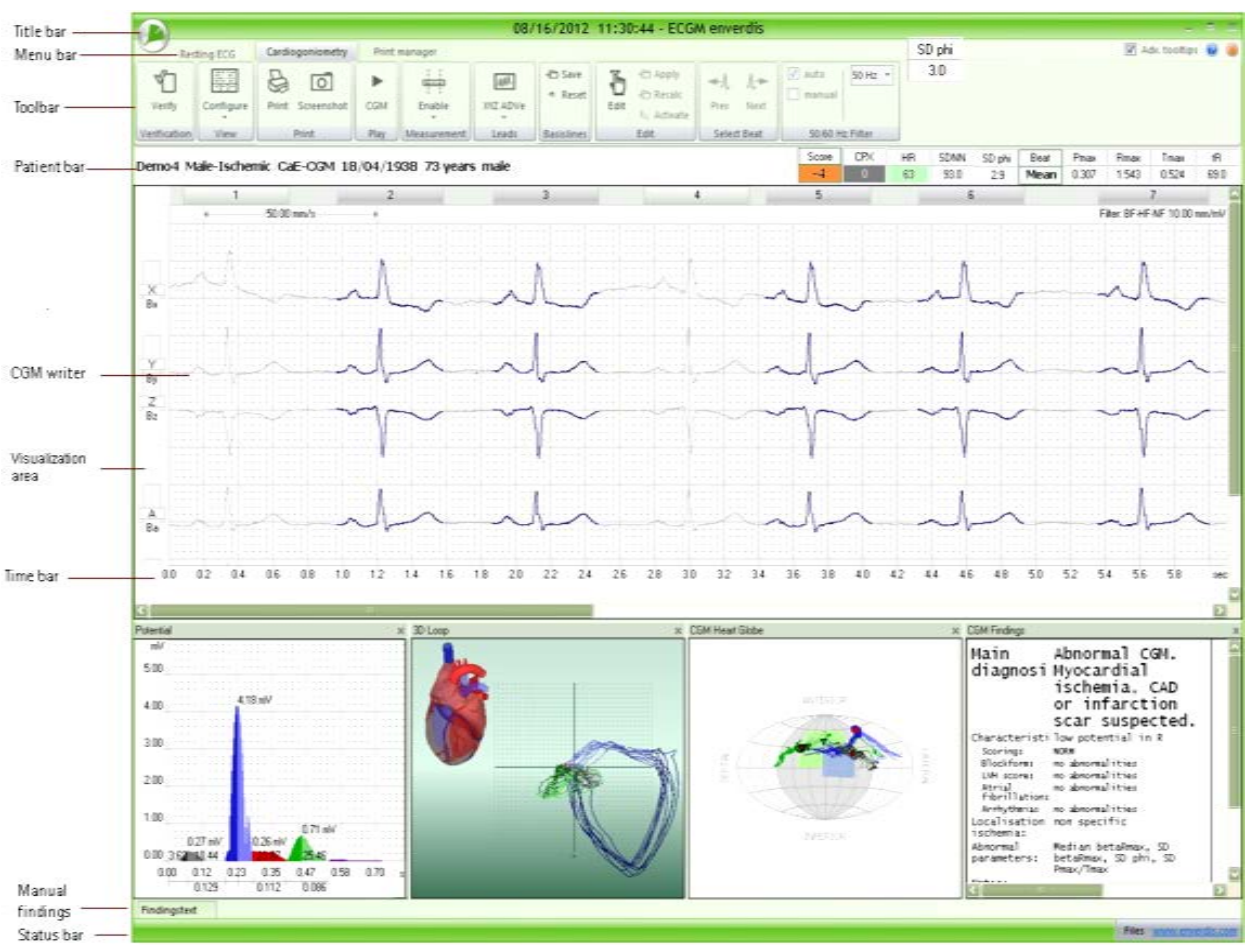

Figure 2. ECG of cardiogoniometry and 3-dimensional registration.

The results of angiography were defined as patients with diagnostic coronary angiography and without CAD. CAD, were defined as stenosis of coronary artery diameter more than 50\%. The other data included age, sex, diabetes, HTN and smoking.

Finally statistical software and statistical methods such as sensitivity Analysis and ROC curve analysis were used to determine sensitivity and specificity.

\section{Results}

The sensitivity, specificity and accuracy of cardiogoniometry by taking angiography as the Gold standard Using sensitivity analysis, and ROC curve Analysis in all participants based on gender, diabetes, blood pressure and smoking were calculated. The results showed that the sensitivity, specificity and accuracy of cardiogoniometry were respectively $79 \%, 56 \%$ and $74 \%$ for men and $60 \%, 63 \%$ and $61 \%$ for women. In diabetic patients, sensitivity, specificity and accuracy of cardiogoniometry were $68 \%, 60 \%$ and $65 \%$ and in non-diabetics were $78 \%, 61 \%$ and $72 \%$. In patients with hypertension sensitivity, specificity and accuracy of cardiogoniometry were $85 \%, 50 \%$ and $63 \%$ and in those without hypertension were $67 \%, 64 \%$ and $71 \%$. Finally, results for sensitivity, specificity and accuracy of cardiogoniometry in smokers were $85 \%, 33 \%$ and $78 \%$ and in nonsmokers were $70 \%, 62 \%$ and $67 \%$. In overall cardiogoniometry revealed a Sensitivity of $73 \%$ and specificity of $60 \%$ and an accuracy of $\% 68$ in detecting CAD (Table 1 ).

The study included 190 patients with the mean age of 57.4 years so that $83(43.7 \%)$ of the patients were female and 107 (56.3\%) were male, 103 (54.2\%) of patients were diabetic, 64 (33.7\%) were hypertensive and 23 (12.1\%) were smokers (Table 2). 
Table 1. Distribution of demographic parameters in patients.

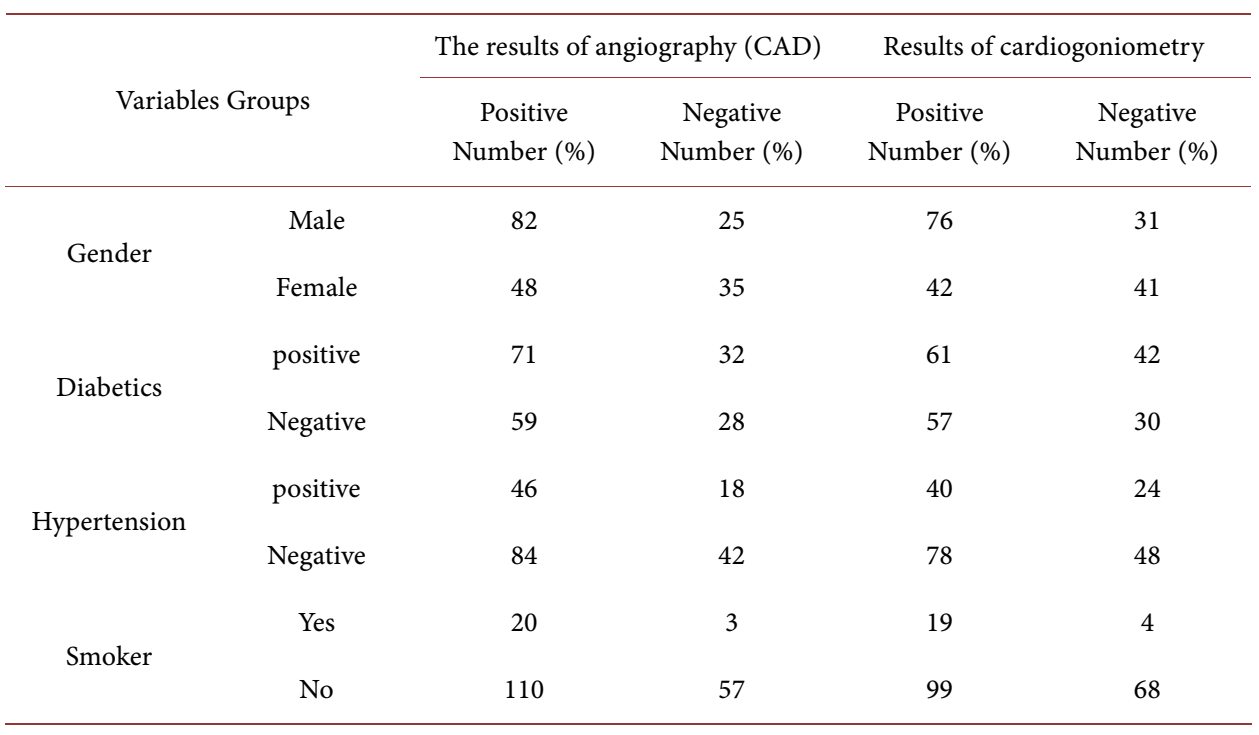

Table 2. CGM and angiography results in all subjects.

\begin{tabular}{cccccc}
\hline & & \multicolumn{3}{c}{ Gold } & \multirow{2}{*}{ Total } \\
\cline { 3 - 5 } & & & Positive & Negative & \\
\hline \multirow{3}{*}{ Test } & Positive & 94 & 24 & 118 \\
& & Negative & 36 & 36 & 72 \\
& & & 130 & 60 & 190 \\
\hline
\end{tabular}

\section{Discussion and Conclusions}

This study aimed to determine the diagnostic value of cardiogoniometry (CGM) as a simple and non-invasive method for the detection of CAD. Results of this study showed that the sensitivity of the cardiogoniometry was more than ECG, but less than perfusion scan and comparable to the exercise test. Its specificity was less than the other three methods. While in most studies sensitivity and specificity of this method were higher than exercise stress test and ECG. Although it is important to note that in a screening test for a high prevalent disease like $\mathrm{CAD}$, sensitivity is more important than specificity.

A study by Meier et al. comparing the diagnostic value of cardiogoniometry with other Noninvasive tests, showed accuracy of $64 \%$ for cardiogoniometry, $55 \%$ for ECG and $80 \%$ for perfusion scan that was almost similar to Stephen Weber's study [9].

In Michael Schupbach et al. study in 2008 which was performed on 793 patients scheduled for coronary angiography, showed sensitivity of $64 \%$ and specificity of $82 \%$ compared with sensitivity of $53 \%$ and specificity of $75 \%$ for ECG [10] that both sensitivity and specificity of cardiogoniometry was more than that of ECG but in this study sensitivity of cardiogoniometry was more and specificity was less than ECG which this difference can be either due to selection of the patients through the people referred for angiography and also the lower sample volume. Saner and colleagues achieved sensitiv- 
ity of $79 \%$ and specificity of $82 \%$ for cardiogoniometry in a study on 50 patients with suspected CAD who underwent coronary angiography that is comparable to the exercise test [11] which was consistent with our study in comparing sensitivity of cardiogoniometry with the exercise test. In vontobel's study the sensitivity of cardiogoniometry was higher and specificity was lower than exercise test [12] although the sensitivity and specificity values of cardiogoniometry in this study were higher than those obtained in ours but in terms of comparison of specificity and sensitivity of cardiogoniometry with stress test was consistent with our study. Anita Sadeghpour et al. evaluated accuracy of cardiogoniometry for diagnosis of ischemia in patients with LBBB at Rajai Tehran Heart Center in 2014. It was showed that cardiogoniometry is not an accurate method for diagnosis of ischemia in patients with LBBB. Of course sample size was small in that study (33 people) [13] and also it was the only study that has been performed in patients with heart failure so that further studies are needed in this field. Stephen Weber and colleagues in a study at 2014 on 100 patients with suspected CAD achieved significantly higher sensitivity and specificity of cardiogoniometry compared with standard 12 lead ECG and slightly less than those of perfusion scan but it was acceptable [14].

In Hebner et al. study in 2010 that compared the cardiogoniometry with troponin test in patients with ACS (acute coronary syndrom), the sensitivity of this method was higher and specificity was lower than troponin test [15]. But in our study, the sensitivity and specificity of cardiogoniometry was lower than those of scan however the sensitivity and specificity of perfusion scan in different centers could vary due to different interpretation In Ralph study at 2012 comparing cardiogoniometry, ECG and troponin for diagnosis of ACS (acute coronary syndrom) and NSTEMI (non ST elevation myocardial infarction) in patients with acute chest pain or dyspnea, it was found that cardiogoniometry shows ischemia before ECG and troponin become positive [16]. This study revealed that cardiogoniometry has a high diagnostic value in settings of ACS and NSTEMI but since our study was performed in patients with stable angina the results are not generalizable to patients with acute coronary syndrome and further studies are needed in this field.

In this study, the sensitivity of cardiogoniometry in men was more than that of women and specificity was fairly similar in the two groups that could be due to a higher incidence of coronary artery disease in men. In smokers and hypertensive patients the sensitivity of the test was more and specificity was less than that of the others but these results are not interpretable due to the small sample size in these two groups. The main limitation of this study was more prevalence of CAD and subsequently high pre-test probability in subjects compared with general population that this could affect the sensitivity and specificity of the test.

The results of this study showed that the accuracy of cardiogoniometry is more than ECG and comparable to the exercise test and can be regarded as a new non-invasive method at rest without certain risks, including exposure to radiation and also is a suitable technique for patients who are not able to exercise. 


\section{References}

[1] Bonow, R.O., Mann, D.L., Zipes, D.P. and Libby, P. (2007) Braunwald's Heart Disease: A Textbook of Cardiovascular Medicine. 8th Edition, Elsevier Science, Philadelphia.

[2] World health Organization the 10 Leading Causes of Death by Broad Income Group (2004) Fact Sheet N 310, Geneva.

[3] Gibbons Raymond, J., Balady Gary, J., Timothy, B.J., Chaitman Bernard, R., Fletcher Gerald, F., Froelicher Victor, F., Mark Daniel, B., McCallister Ben, D., Mooss Aryan, N., O’Reilly Michael, G., et al. (2002) ACC/AHA 2002 Guideline Update for Exercise Testing: Summary Article: A Report of the American College of Cardiology/American Heart Association Task Force on Practice Guidelines (Committee to Update the 1997 Exercise Testing Guidelines). Circulation, 106, 1883-1892.

http://dx.doi.org/10.1161/01.CIR.0000034670.06526.15

[4] http://www.physionet.org/physioblank/database/mitdb

[5] Drew, B.J., Pelter, M.M., Lee, E., et al. (2005) Designing Prehospital ECG Systems for Acute Coronary Syndromes. Lessons Learned from Clinical Trials Involving 12-Lead ST-Segment Monitoring. Journal of Electrocardiology, 38, 180-185. http://dx.doi.org/10.1016/j.jelectrocard.2005.06.031

[6] Herrmann, H.J. and Meier, A.P. (1989) Does the Cardiogoniogram Change Following Revascularization? Schweizerische Medizinische Wochenschrift, 119, 979-983.

[7] Zhang, Z.-N., Zhang, H. and Zhuang, T.-G. (1987) One-Dimensional Extraction of Paper-Written ECG Image and Its Archiving. SPIE Proceedings: Digital Image Processing in Medicine, 845, 419-422.

[8] Hubner, T., Schupbach, W.M., Seeck, A., et al. (2010) Cardiogoniometric Parameters for Detection of Coronary Artery Disease at Rest as a Function of Stenosis Localization and Distribution. Medical \& Biological Engineering \& Computing, 48, 435-446. http://dx.doi.org/10.1007/s11517-010-0594-1

[9] Meier, A., Höflin, F., Herrmann, H.J., Wolf, C., Gurtner, H.P. and Rösler, H. (1987) Comparative Diagnostic Value of a New Computerized Vectorcardiographic Method (Cardiogoniometry) and Other Noninvasive Tests in Medically Treated Patients with Chest Pain. Clinical Cardiology, 10, 311-316. http://dx.doi.org/10.1002/clc.4960100504

[10] Schupbach, W.M., Emese, B., Loretan, P., et al. (2008) Non-Invasive Diagnosis of Coronaryartery Disease Using Cardiogoniometry Performed at Rest. Swiss Medical Weekly, 138, 230-238.

[11] Saner, H., Baur, H.R., Sanz, E. and Gurtner, H.P. (1983) Cardiogoniometry: A New Noninvasive Method for Detection of Ischemic Heart Disease. Clinical Cardiology, 6, 207-210.

[12] Vontobel, H., Tartini, R. and Steinbrunn, W. (1988) Cardiogoniometry in Coronary Heart Disease. A Clinical Study. Schweizerische Medizinische Wochenschrift, 118, 1609-1611.

[13] Sadeghpour, A., Alizadehasl, A., Diz, A.A., Akbarzadeh, M.A., Rezaeian, N., Zeighami, M. and Hashemi, A. (2014) Rajaie Cardiovascular Medical and Research Center, Ir Is There any Difference in Cardiogoniometry Parameters of Ischemic and Non-Ischemic Cardiomyopathy in Patients with Left Bundle Branch Block? Archives of Cardiovascular Imaging, 2. http://dx.doi.org/10.1007/s00392-012-0452-2

[14] Weber, S., Birkemeyer, R., Schultes, D., Grewenig, W. and Huebner, T. (2014) Comparison of Cardiogoniometry and ECG at Rest versus Myocardial Perfusion Scintigraphy. Annals of Noninvasive Electrocardiology, 19, 462-470. http://dx.doi.org/10.1111/anec.12151

[15] Hubner, T., Gornig, M., Schupbach, M., et al. (2010) Electrocardiologic and Related Me- 
thods of Non-Invasive Detection and Risk Stratification in Myocardial Ischemia: State of the Art and Perspectives. German Medical Science, 8.

[16] Tölg, R., Zeymer, U., Birkemeyer, R., Wessely, R., Eggebrecht, H., Bocksch, W., Schneider, S., Richardt, G. and Hamm, C. (2012) Cardiogoniometry as a Diagnostic Tool in Patients with Acute Coronary Syndromes: Results of the CGM@ACS Trial. Clinical Research in Cardiology, 101, 727-736. http://dx.doi.org/10.1007/s00392-012-0452-2

Submit or recommend next manuscript to SCIRP and we will provide best service for you:

Accepting pre-submission inquiries through Email, Facebook, LinkedIn, Twitter, etc.

A wide selection of journals (inclusive of 9 subjects, more than 200 journals)

Providing 24-hour high-quality service

User-friendly online submission system

Fair and swift peer-review system

Efficient typesetting and proofreading procedure

Display of the result of downloads and visits, as well as the number of cited articles

Maximum dissemination of your research work

Submit your manuscript at: http://papersubmission.scirp.org/

Or contactwjcd@scirp.org 